\title{
A STUDY OF CLINICAL, METABOLIC AND HAEMATOLOGICAL PROFILE IN INFANTS OF DIABETIC MOTHERS, KARAD
}

\author{
Allappa Mallappa Koppad ${ }^{1}$, Mandar Namdeo Karanjkar², Akhila Sukumaran ${ }^{3}$ \\ ${ }_{1}^{1}$ Professor, Department of Paediatrics, Krishna Institute of Medical Sciences Deemed University, Karad. \\ ${ }^{2}$ Assistant Professor, Department of Paediatrics, Krishna Institute of Medical Sciences Deemed University, Karad. \\ ${ }^{3}$ Resident, Department of Paediatrics, Krishna Institute of Medical Sciences Deemed University, Karad.
}

\begin{tabular}{l}
\hline ABSTRACT \\
BACKGROUND \\
Diabetes is one of the most common metabolic disorder complicating pregnancy. Infants born to diabetic mothers (IDMs) are at \\
increased risk of serious complications compared to those of nondiabetic mothers. This study focuses on various clinical, metabolic \\
and haematological complications of infants of diabetic mothers, both gestational and pregestational diabetes.
\end{tabular}

\section{MATERIALS AND METHODS}

This hospital-based prospective observational study was conducted in Krishna Institute of Medical Sciences Deemed University, Karad, Maharashtra, over a period of 9 months duration. 25 infants of diabetic mothers admitted to the NICU were included in the study. Maternal history regarding diabetes mellitus was obtained and complete neonatal examination was performed and recorded. Relevant biochemical and haematological tests as well as echocardiography was conducted in all the neonates.

\section{RESULTS}

Of the 25 neonates, 21 (84\%) were born to mothers with gestational diabetes and 4 (16\%) were born to mothers with pregestational diabetes. Most of them, 14 (56\%) were delivered by normal vaginal delivery. 2 (8\%) were born prematurely. Majority of them were AGA (68\%). The most common haematological and metabolic abnormalities recorded were hypoglycaemia (32\%), polycythaemia (56\%) and hyperbilirubinaemia (48\%). Congenital malformations were seen in $28 \%$ babies in the form of heart disease. There were no neonatal deaths in our study.

\section{CONCLUSION}

Maternal diabetes has an adverse effect on foetal growth, glucose metabolism, oxygenation and preparation for extrauterine life. Our study suggests that hypoglycaemia and polycythaemia remain the most common complication in infants of diabetic mothers. They are also at a greater risk for congenital heart diseases.

\section{KEYWORDS}

Gestational Diabetes Mellitus, Hypoglycaemia, Polycythaemia, Macrosomia, Echocardiography.

HOW TO CITE THIS ARTICLE: Koppad AM, Karanjkar MN, Sukumaran A. A study of clinical, metabolic and haematological profile in infants of diabetic mothers, Karad. J. Evolution Med. Dent. Sci. 2017;6(73):5217-5220, DOI: 10.14260/Jemds/2017/1133

\section{BACKGROUND}

The prevalence of diabetes is increasing globally and India is no exception. ${ }^{1}$ In India, the prevalence of GDM among urban women is higher than that among rural women, which could be due to urbanisation and higher BMI in these women.2 Diabetes mellitus is a chronic metabolic disorder due to either insulin deficiency (relative or absolute) or due to peripheral tissue resistance (decreased sensitivity) to the action of insulin. ${ }^{3}$ Infants born to diabetic mothers are at increased risk for stillbirth, congenital malformations and perinatal morbidity and mortality. ${ }^{4}$ Macrosomia, hypoglycaemia, polycythaemia and congenital heart diseases are more seen in these infants. Also, they are at greater risk of developing birth asphyxia and respiratory distress syndrome. ${ }^{5}$

Financial or Other, Competing Interest: None.

Submission 05-08-2017, Peer Review 30-08-2017,

Acceptance 04-09-2017, Published 11-09-2017.

Corresponding Author:

Dr. Akhila Sukumaran,

Room No. 309, IHR Hostel,

KIMSDU, Karad-415110,

Satara District, Maharashtra.

E-mail: drakhila90@hotmail.com

DOI: $10.14260 /$ jemds/2017/1133
The causes for these complications are likely multifactorial and many of these are due to the effect of poor maternal glycaemic control on the foetus ${ }^{6}$ and can be prevented by periconceptional and prenatal care.

\section{Aims and Objectives}

To study various clinical, metabolic and haematological complications of infants of diabetic mothers, both gestational and pregestational diabetes in Krishna Institute of Medical Sciences, Karad, Maharashtra.

\section{MATERIALS AND METHODS}

This hospital-based prospective observational study was conducted in the neonatal unit of Krishna Institute of Medical Sciences, Karad, from November 2016 to July 2017. Institutional ethical committee approval was taken before starting the study.

\section{Inclusion Criteria}

All singleton neonates born to diabetic mothers (booked cases in our hospital) who were on treatment with oral hypoglycaemic agents or insulin.

\section{Exclusion Criteria}

- Neonates of diabetic mothers who were not booked at our hospital. 
- Neonates of diabetic mothers with multiple medical complications like heart disease, renal disease, hypertensive disorders of pregnancy.

- Twin neonates of diabetic mothers.

\section{MATERIALS AND METHODS}

A total of 25 neonates of diabetic mothers shifted to NICU met the inclusion criteria and were enrolled in the study. Informed written consent was obtained from the parents/guardians prior to enrolment of their babies in the study.

Mothers known to have diabetes mellitus before conception were labelled as pregestational diabetes and those mothers who developed glucose intolerance during the course of pregnancy were labelled as gestational diabetes. Relevant information about the mothers such as the maternal age, parity, gestational age, diabetes status, etc. were obtained. Detailed physical examination of the neonate was done and recorded in the predesigned proforma. Infants born with birth weight greater than $90^{\text {th }}$ percentile for gestational age was considered Large for Gestational Age (LGA), babies born between $10^{\text {th }}$ and $90^{\text {th }}$ percentile were considered Appropriate for Gestational Age (AGA) and less than 10 th percentile as Small for Gestational Age (SGA). Babies with birth weight more than $4 \mathrm{~kg}$ was termed macrosomic.

The neonates were started on hourly feeds in NICU. The first feed was given within 1 hour of birth and they were fed hourly for the first 6 hours and then two-hourly if blood glucose values were normal. Blood glucose levels were checked at $1,2,3,6,12,24,36$ and 48 hours using a glucometer. This method was used for screening purpose and for prompt identification of hypoglycaemia. If the baby was found hypoglycaemic, peripheral venous blood glucose estimation was done. Hypoglycaemia was defined as blood glucose level of $\leq 47 \mathrm{mg} / \mathrm{dL}$ in any infant regardless of gestational age and whether or not symptoms were present. Normoglycaemic babies were transferred back to the mother and started on breast feeds. Babies who remained hypoglycaemic despite adequate feeds were started on intravenous dextrose infusion. Haemoglobin, haematocrit, serum calcium and magnesium were evaluated at admission and later when required. Polycythaemia was defined as venous haematocrit (PCV) of more than $65 \%$ or a venous haemoglobin concentration more than $22 \mathrm{~g} / \mathrm{dL}$. Hypocalcaemia was defined as total serum calcium less than 7 $\mathrm{mg} / \mathrm{dL}$ and hypomagnesaemia as serum magnesium level of less than $1.7 \mathrm{mg} / \mathrm{dL}$. If the neonate was found to be icteric, estimation of serum bilirubin was done and phototherapy was started if it was significant. Hyperbilirubinaemia was defined as serum bilirubin level of $\geq 15 \mathrm{mg} / \mathrm{dL}$. Echocardiography was done in all the cases and cardiac complications were recorded. Neurosonography was done in all those neonates who had birth asphyxia. Where needed, x-ray chest, ABGs, total count, blood culture, urea, creatinine were done. A p value of $<0.05$ was considered significant.

\section{RESULTS}

Total number of neonates included in the study were 25 . Among them, 21 (84\%) were gestational diabetic mothers and $4(16 \%)$ were pregestational diabetic mothers (Table 1). There were 12 (48\%) male babies and 13 (52\%) female babies (Table 2). Most of them, 14 (56\%) were delivered by normal vaginal delivery, $2(8 \%)$ by instrumental delivery and the rest
9 (36\%) by C-section (Table 2). Of 25 neonates, only 2 (8\%) were born prematurely (Table 3$)$. Out of all $(n=25), 4$ babies were LGA, 17 were AGA and the rest were SGA (Table 3).

Macrosomia was noted only in $3(12 \%)$ babies (Table 4$) .3$ (12\%) out of 25 babies developed perinatal asphyxia. Out of these, 2 were neonates of GDM mothers and 1 belonged to mother with PGDM, although the difference is not significant statistically ( $p$ >0.05). One baby developed sepsis. Hypoglycaemia was the most common metabolic abnormality noted as shown in Table 5. Hypocalcaemia and hypomagnesaemia was seen in $16 \%(4 / 25)$ and $12 \%(3 / 25)$ neonates, respectively. Among the haematological abnormalities, polycythaemia was the most common, presenting in 14 (56\%) neonates (Table 5). The next common abnormality was hyperbilirubinaemia and was seen in 11 (52.3\%) and 1 (25\%) neonates of GDM and PGDM mothers, respectively. $28 \%(7 / 25)$ neonates had congenital heart disease of which ostium secundum ASD was the most common type seen in $4(57.14 \%)$ neonates (Table 6). No birth injuries or structural anomalies were seen in any of the neonates in our study. There was no mortality as well (Table 7).

\begin{tabular}{|c|c|c|}
\hline $\begin{array}{c}\text { Diabetic Status of } \\
\text { the Mother }\end{array}$ & No. of Neonates (n=25) & Percentage \\
\hline GDM & 21 & 84 \\
\hline PGDM & 4 & 16 \\
\hline \multicolumn{2}{|c|}{ Table 1. Distribution of Neonates } \\
According to Type of Maternal Diabetes \\
\hline
\end{tabular}

\begin{tabular}{|c|c|c|}
\hline & No. of Neonates (n=25) & Percentage \\
\hline Gender Distribution & 12 & 48 \\
Male & 13 & 52 \\
Female & 14 & 56 \\
\hline Mode of Delivery & 2 & 8 \\
Vaginal delivery & 9 & 36 \\
C-section & \\
Instrumental & Table 2. Gender Distribution and \\
\hline \multicolumn{2}{|c|}{ Mode of Delivery of the Neonates } \\
\hline
\end{tabular}

\begin{tabular}{|c|c|c|}
\hline & No. of Neonates (n=25) & Percentage \\
\hline $\begin{array}{c}\text { Gestational Age } \\
\text { Preterm }\end{array}$ & 2 & 8 \\
Term & 23 & 92 \\
\hline Weight for & & \\
Gestational Age & 4 & 16 \\
SGA & 17 & 68 \\
AGA & 4 & 16 \\
LGA & & \\
\hline \multicolumn{2}{|c|}{ Table 3. Gestational Age and Weight } \\
for Age Distribution of Neonates \\
\hline
\end{tabular}

LGA- Large for gestational age, AGA- Appropriate for gestational age, SGA- Small for gestational age.

\begin{tabular}{|c|c|c|}
\hline Birth Weight (g) & No. of Neonates $(n=25)$ & Percentage \\
\hline 1500-1999 & 2 & 8 \\
\hline $2000-2499$ & 1 & 4 \\
\hline $2500-2999$ & 7 & 28 \\
\hline $3000-3499$ & 7 & 28 \\
\hline $3500-4000$ & 5 & 20 \\
\hline$>4000$ & 3 & 12 \\
\hline
\end{tabular}




\begin{tabular}{|c|c|c|}
\hline Abnormality & Neonates & Percentage \\
\hline Hypoglycaemia & 8 & 32 \\
GDM & 5 & \\
PGDM & 3 & 16 \\
\hline Hypocalcaemia & 4 & \\
GDM & 3 & 12 \\
PGDM & 1 & \\
\hline Hypomagnesaemia & 3 & 56 \\
GDM & 1 & \\
PGDM & 2 & 48 \\
\hline Polycythaemia & 14 & \\
GDM & 13 & \\
PGDM & 1 & \\
\hline Hyperbilirubinaemia & 12 & \\
GDM & 1 & \\
PGDM & Table 5. Metabolic and Haematological \\
\multicolumn{2}{|c|}{ Abnormalities of the Neonates } \\
\hline
\end{tabular}

\begin{tabular}{|c|c|c|}
\hline Congenital Heart Disease & No. of Neonates (7/25) & $\mathbf{\%}$ \\
\hline ASD & 4 & 57.1 \\
\hline VSD & 1 & 14.3 \\
\hline PDA & 1 & 14.3 \\
\hline PPHN & 1 & 14.3 \\
\hline \multicolumn{2}{|c|}{ Table 6. Congenital Heart Diseases Among the Neonates } \\
\hline
\end{tabular}

ASD- Atrial septal defect, VSD- Ventricular septal defect, PDA- Patent ductus arteriosus, PPHN- Persistent pulmonary hypertension of the newborn.

\begin{tabular}{|l|c|c|}
\hline Outcome & No. of Neonates (n=25) & Percentage \\
\hline Mortality & 0 & 0 \\
\hline Improved & 25 & 100 \\
\hline \multicolumn{2}{|c|}{ Table 7. Outcome of the Neonates } \\
\hline
\end{tabular}

\section{DISCUSSION}

GDM poses a formidable threat to both mother and the child. In our study, total number of infants of diabetic mothers were 25 . Among them, 21 were gestational diabetic mothers and 4 were pregestational diabetic mothers. In a similar study conducted in Karnataka, out of 69 neonates, 49 (71.01\%) were gestational diabetic mothers and 20 (28.99\%) were pregestational diabetic mothers. ${ }^{7}$ These neonates may need to be delivered prematurely due to maternal or foetal problems. Ranade et $\mathrm{al}^{8}$ reported $36 \%$ of the IDMs to be preterm. In this study, the $8 \%$ IDMs were delivered by caesarean section as compared to $56 \%$ normal delivery. This is opposed to most of the other studies were rate of caesarean sections were more among IDMs..$^{8-9}$ Macrosomia is one of the major problems in these babies leading to birth injuries and perinatal asphyxia. ${ }^{10}$

In this study, only $12 \%(3 / 25)$ babies were macrosomic, which may be due to better glycaemic control in the mothers. Fifteen percent IDMs suffered from birth asphyxia in Alam's study. ${ }^{11}$ No baby in our study had birth injury. All the macrosomic babies in our study developed perinatal asphyxia, in spite of being delivered by caesarean section. This shows that there are other factors that contribute to asphyxia apart from maternal diabetes. These include placental vascular disease and reduced placental blood flow in maternal diabetes. ${ }^{12}$

According to Pedersen hypothesis, ${ }^{13}$ maternal hyperglycaemia results in foetal hyperglycaemia because glucose readily traverses placenta. Due to this, after 20 weeks of gestation, when the foetal pancreas starts functioning, there occurs hypertrophy of foetal pancreatic cells and hyperinsulinaemia. Among the different metabolic errors, hypoglycaemia was the most commonly observed one in our study appearing in 32\% neonates. Among these, 8 (32\%) neonates, only 3 were symptomatic probably due to early introduction of feeds. Lethargy and jitteriness were the symptoms observed. One baby developed seizures. The occurrence of hypoglycaemia was higher in infants of PGDM $(3 / 4)$ mothers as compared to that of GDM mothers $(5 / 21)$ and the difference was statistically significant $(\mathrm{p}<0.05)$. Similar study by Mahmood ${ }^{14}$ reported higher incidence of hypoglycaemia in infants of mothers with pregestational diabetes $(38.09 \%)$ as compared to mothers with gestational diabetes $(12.9 \%)$. Hypocalcaemia was seen in $16 \%$ cases. Out of these, $14.28 \%$ and $25 \%$ belonged to GDM and PGDM mothers, respectively. None of the babies were symptomatic. Similar studies like Ranade et $\mathrm{al}^{8}$ and Deorari et al ${ }^{15}$ reported the incidence of hypocalcaemia to be $14 \%$ and $13 \%$, respectively. Hypomagnesaemia was seen in $12 \%$ neonates, 1 in GDM and 2 in PGDM group and the result was statistically significant $\quad(\mathrm{p}<0.05)$. Both hypercalcaemia and hypomagnesaemia was higher in PGDM group. Similar observation was seen in the study conducted by Nili et al. ${ }^{16}$

In our study, 14 (56\%) infants developed polycythaemia of which $61.9 \%$ belonged to infants of GDM mothers and 25\% belonged to PGDM mothers. The result was not statistically significant. These babies were treated conservatively. Hyperbilirubinaemia was noted in $48 \%$ babies $(52.3 \%$ GDM and 25\% PGDM). Incidence of both polycythaemia and hyperbilirubinaemia was higher in GDM group. Similar observation was seen in Gopal et al. ${ }^{7}$

The association of maternal diabetes mellitus and congenital malformations is well established. The risk of child's malformation in IDMs is three to four times greater than in infants of nondiabetic mothers. All types of DM can produce a large spectrum of CHD. Congenital heart diseases were seen in 7 neonates (28\%), of which atrial septal defect (ostium secundum) was the most common type (4/7 neonates). Incidence of CHDs in Gopal et al was $11.6 \%$.

Perinatal mortality amongst offspring of diabetic mothers has remained high and was previously an indication for termination of pregnancy. The cause of increased perinatal morbidity and mortality is not known, but has been attributed to increased insulin levels leading to hyperanabolism. Studies have shown higher mortality amongst infants of diabetic mothers compared to controls. ${ }^{17-19}$ However, no mortality was recorded in our study.

The limitation of our study included the small sample size and a lack of detailed profile of maternal blood glucose in each trimester.

\section{CONCLUSION}

Advances in maternal and neonatal medicine has contributed to a reduction in adverse outcomes of infants born to mothers with impaired glucose tolerance during pregnancy. However, the risks for spontaneous abortion, stillbirth, congenital malformations and perinatal mortality and morbidity still exist. Therefore, it is highly important to screen all pregnant women for GDM. Such patients should have a regular follow- 
up in order to maintain a strict glycaemic control in order to have a satisfactory neonatal outcome.

\section{REFERENCES}

[1] Seshiah V, Balaji V, Balaji MS, et al. Gestational diabetes mellitus in India. JAPI 2004;52:707-11.

[2] Zargar AH, Sheikh MI, Bashir MI, et al. Prevalence of gestational diabetes mellitus in Kashmiri women from the Indian subcontinent. Diabetes Research and Clinical Practice 2004;66(2):139-45.

[3] Dutta DC. Diabetes mellitus in pregnancy. In: Dutta DC. edr. Text book of Obstetrics. 7th edn. Calcutta: New Central Book Agency 2011: p. 281.

[4] Nold JL, Georgieff MK. Infants of diabetic mothers. Pediatric Clinics of North America 2004;51(3):619-37.

[5] Rudge MV, Calderon IM, Ramos MD, et al. Perinatal outcome of pregnancies complicated by diabetes and by maternal daily hyperglycemia not related to diabetes. A retrospective 10-year analysis. Gynecologic and Obstetric Investigation 2000;50(2):108-12.

[6] Widness JA. Fetal risks and neonatal complications of diabetes mellitus and metabolic and endocrine disorders. In: Brody SA, Ueland K. eds. Endocrine disorders in pregnancy. Norwalk (CT): Appleton-Lang 1989:273-97.

[7] Gopal G. A study of clinical, metabolic and hematological profile in infants of diabetic mothers. Indian Journal of Pharmaceutical and Biological Research 2014;2(2):34-40.

[8] Ranade AY, Merchant RH, Bajaj RT, et al. Infants of diabetic mothers- An analysis of 50 cases. Indian Pediatrics 1989;26(4):366-70.

[9] Moshin F. Glucose and calcium profile in infants of diabetic mothers. An analysis of 100 cases - A hospitalbased study (dissertation). Dhaka: BSMMU 1999.

[10] Meur S, Mann NP. Infant outcomes following diabetic pregnancies. Paediatrics and Child Health 2007;17(6): 217-22.
[11] Alam M, Raza SJ, Sherali AR, et al. Neonatal complications in infants born to diabetic mothers. Journal of the College of Physicians and Surgeons Pakistan JCPSP 2006;16(3):212-5.

[12] Mimouni F, Miodovnik M, Siddiqi TA, et al. Perinatal asphyxia in infants of insulin-dependent diabetic mothers. The Journal of Pediatrics 1988;113(2):34553.

[13] Pedersen J. The pregnant diabetic and her newborn: problems and management. 2nd edn. Munksgaard 1977.

[14] Mahmood CB, Kayes MI. Problems and immediate outcome of infants of diabetic mothers. Journal of Bangladesh College of Physicians and Surgeons 2008;26(2):67-72.

[15] Deorari AK, Kabra SK, Paul VK, et al. Perinatal outcome of infants born to diabetic mothers. Indian Pediatr 1991;28(11):1271-5.

[16] Nili F, Mahdaviani A. Comparison of morbidities between infants of pregestational \& gestational diabetic mothers. Medical Journal of The Islamic Republic of Iran (MJIRI) 2004;18(1):13-9.

[17] Butte NF. Carbohydrate and lipid metabolism in pregnancy: normal compared with gestational diabetes mellitus. The American Journal of Clinical Nutrition 2000;71(5):1256s-61s.

[18] Ferrara A, Hedderson MM, Quesenberry CP, et al. Prevalence of gestational diabetes mellitus detected by the national diabetes data group or the carpenter and coustan plasma glucose thresholds. Diabetes Care 2002;25(9):1625-30.

[19] Otolorin EO, Famuyiwa 00, Bella AF, et al. Reproductive performance following active management of diabetic pregnancies at the University College Hospital, Ibadan, Nigeria. Afr J Med Med Sci 1985;14(3-4):155-60. 